\title{
FEMINISMO JURÍDICO - ESTE NOSSO (DES)CONHECIDO
}

\author{
Dra. Salete Maria da Silva \\ Advogada, Professora do Bacharelado em Estudos de Gênero e Diversidade (UFBA), do \\ Programa de Pós-Graduação (Mestrado e Doutorado) em Estudos Interdisciplinares sobre \\ Mulheres, Gênero e Feminismo - PPGNEIM/UFBA e do Programa de Pós-Graduação \\ (Mestrado) em Segurança Pública, Justiça e Cidadania-PROGESP/UFBA.
}

\section{RESUMO DA PALESTRA ${ }^{1}$}

\section{Proposta:}

A palestrante se propôs a apresentar e refletir sobre o feminismo jurídico, destacando-o como um pensamento/movimento ainda desconhecido no âmbito das escolas de Direito e do sistema de Justiça. Além disto, dedicou-se a pontuar as sutis diferenças entre teoria feminista do Direito e feminismo jurídico propriamente dito. Por fim, destacou a importância da incorporação da perspectiva de gênero no Direito e advogou por um maior diálogo entre os grupos de pesquisa que tratam da interface entre feminismo e práticas jurídicas.

\section{Considerações iniciais:}

A palestrante iniciou sua exposição a partir de três palavras chaves: a primeira foi o termo feminismo, que já vem sendo objeto de pesquisa há bastante tempo no âmbito dos estudos de gênero e/ou sobre mulheres. Destacou a necessidade de se abordar o feminismo no plural, dada as suas diversas vertentes e abordagens. A segura palavra-chave foi o termo jurídico - apontado pela palestrante como uma expressão plurívoca, já que trata de diversas formas de se realizar ou de se materializar o Direito, tal como o direito enquanto produto da cultura, enquanto sistema normativo e enquanto estrutura, instituição e habitus. Por último, trouxe a palavra "desconhecido" - para se referir à situação dos estudos jurídicos na atualidade, no que tange à interface entre feminismo e direito, pontuando que existe uma ignorância acerca da interação entre ambos os termos, pois apesar de existirem inúmeros grupos trabalhando sobre isso, muito mais existem pessoas que inexploram ou mesmo ignoram os impactos

\footnotetext{
${ }^{1}$ Transcrição realizada pela graduanda Fernanda Victória Meneses da Silva, com ajustes indicados pela palestrante, de palestra realizada em 28 de maio de 2019 para o Grupo de Pesquisa Direito e Sexualidade, na Faculdade de Direito da Universidade Federal da Bahia.
} 
que o Direito exerce sobre as convenções sociais de gênero e como o gênero também contribui para a constituição do Direito. Destacou que esta questão chega a ser incompreendida até mesmo por muitas feministas não juristas que trabalham sobre a temática.

\section{Como articular feminismo e Direito?}

Sequencialmente, levantou a seguinte questão: feminismo e direito se articulam bem? E destacou, pormenorizadamente, a relação histórica e (in)tensa entre ambos os fenômenos. Neste momento ela sustentou que sim, existem relações históricas e intensas entre feminismo e direito, pontuando que estas relações nem sempre foram teorizadas, mas sempre existiram, pois desde que existe o feminismo enquanto movimento/pensamento, existe uma relação entre feminismo e direito. Afirmou que não se trata de uma relação considerada tranquila, pois existem determinados feminismos que dialogam melhor com 0 campo jurídico, principalmente aqueles pautados nos ideais iluministas, nas ideias de igualdade e inclusão, e outros que miram o direito ainda com desconfiança. Por isso, segundo ela, convém destacar que nem todo feminismo liberal é "imprestável", como dizem algumas ativistas.

A seguir, informou que é possível catalogar várias relações históricas entre feminismo e Direito, conforme as apresentadas por ela num slide (exibiu imagens de mulheres atuando na Revolução Francesa, nas lutas pelo direito ao voto em vários países, nas lutas pelo acesso à educação, lutas contra a ditadura, contra a violência de gênero, pelo direito ao aborto e outras pautas históricas nas quais o debate sobre direitos esteve sempre presente. Pontuou que as mulheres sempre lutaram por direitos, seja de forma individual ou coletivamente. Enfatizou o exemplo do movimento mães de maio, nascido na baixada santista, informando que estas mulheres entram na cena pública a partir de acontecimentos que levaram à negação de suas maternidades, posto que foram privadas da convivência com seus filhos em virtude da violência estatal. $E$, não por coincidência, são, em sua maioria, mulheres negras, mães de homens negros cujas vidas foram ceifadas pela violência policial. Neste momento ela destacou a diversidade de lutas que as mulheres travaram e ainda travam, pugnando, historicamente, em prol de seus direitos humanos, dos direitos de seus dependentes, assim como a complexidade das pautas, bandeiras e até mesmo teorias e visões, que as vezes aparentam carregar certas contradições, dada a existência de outros marcadores sociais, como raça e classe que atravessam a realidade destas mulheres. Por exemplo: as teorias feministas radicais sustentavam que a maternidade atrapalhava o exercício da cidadania das mulheres, dado a divisão sexual do trabalho e os papéis de gênero socialmente impostos às mulheres. No entanto, em virtude da diversidade de experiências 
femininas, é possível perceber que muitas mulheres adentraram ao espaço público precisamente na luta por direitos a partir de sua condição de mãe, seja reivindicando direitos sociais, como o direito à creche e à escola para os filhos, seja demandando por direitos sexuais e reprodutivos, incluindo-se aí a possibilidade de se vivenciar uma gravidez desejada, saudável e amparada pelo Estado e pela sociedade, etc, sem olvidar da questão do aborto, dentre outras.

\section{Percepções feministas sobre o Direito}

Quanto às percepções das feministas acerca do Direito, destacou que não há e nunca houve uma visão uniforme, pacífica ou consensual das feministas acerca do fenômeno jurídico, ou mesmo sobre o sistema de justiça, pois, assim como qualquer outro campo teórico ou político, há muitas disputas internas e externas, inclusive de natureza teórico-conceitual ou de estratégica política.

Afirmou que as percepções variam no tempo e no espaço, pois, a seu ver, não se faz transformações sociais sem que a arena jurídica seja disputada, seja teoricamente ou politicamente, ou seja, não se faz debate teórico sem debate político. Destarte, se o feminismo é uma luta na qual o direito ocupa questão central, o que tem sido dito historicamente sobre isso? As feministas vão diferir quanto à percepção. As primeiras, segundo ela, vão pensar o direito como algo que domina as mulheres e só. Eis porque sustentavam que o direito é sexista pontuando que o sexismo é precisamente uma "ideologia de gênero", ou seja, uma visão segundo a qual determinado sexo é superior a outro, e, no caso de sociedades patriarcais, acredita-se que os homens são naturalmente superiores às mulheres. Esta visão de que o Direito é sexista corresponde às feministas liberais, do chamado feminismo de $1^{\underline{a}}$ onda. Ela pontua que existem críticas à divisão do feminismo em ondas, mas a adoção desta abordagem é útil para entendermos o contexto histórico de cada fase do mencionado movimento, assim como suas demandas.

Segundo a palestrante, é precisamente nessa primeira versão do feminismo que se vai falar em igualdade. Afinal, aqui as influências filosóficas advêm do iluminismo. $O$ debate em torno da participação política ou sobre 0 ingresso das mulheres no mercado de trabalho e nas instituições de ensino está presente nesta fase. E é um debate que segue atual até hoje, afinal, nem toda mulher que está em desempenhando uma função laboral ou que ocupa cargo de poder é, necessariamente, empoderada, mas este é outro debate. Essa visão inicial vai da Revolução Francesa até o fim da $1^{\underline{a}}$ Guerra Mundial, onde a luta visava estender o direito dos homens às mulheres. Como foi dito, este primeiro momento tem inspiração liberal e iluminista - eis porque não se pode desprezar 
a contribuição do pensamento liberal na constituição do feminismo de primeira onda. E seus reflexos podem ser percebidos até hoje.

As feministas radicais da década de 60 e 70, por sua vez, destacaram que não bastava só mudar a lei, pois era preciso mudar a cultura, eis porque criticaram alguns institutos jurídicos, já que a mera existência dos mesmos não cambiava a vida das mulheres. Falaram de diferença, ao contrário do contexto anterior, que focava unicamente na igualdade. Esta abordagem pôs ênfase na diferença e na cultura para dizer que as leis devem atender as necessidades e especificidades das mulheres - lembrando que, no início, se falava apenas na condição de mulheres cis, embora este termo sequer existisse. Este tipo de feminismo afirmava que o direito era masculino e, portanto, era preciso mudar a cultura e também a estrutura social majoritariamente androcêntrica. Trata-se de uma perspectiva múltipla. Não se trabalhava com o conceito de gênero, ainda, mas sim, com a noção de patriarcado, tinha forte influência marxista, embora também fizesse críticas ao marxismo, mas tomava emprestado deste as ideias de dominação, exploração, divisão do trabalho, só que neste caso, a divisão era sexual e não social como afirmava Marx.

Na sequência ela falou de uma abordagem que sustenta que o direito tem gênero, e que, portanto, não é somente masculino ou somente patriarcal. 0 direito, nesta nova visão, não é, por si só, algo "nefasto", é um produto da cultura e, como tal, também produz discursos e práticas, podendo, eventualmente, ser emancipatório. Esta fase do feminismo acredita que as ideias feministas podem contaminar o direito para que este possa atuar como um contradiscurso, como um instrumento de inclusão. Essa é a terceira onda, denominada de pósmoderna. Ou seja, aqui o Direito tanto constrói como é construído pelo gênero, afinal, é o direito que afirma quem pode constituir família, quem pode adotar crianças, quem pode vivenciar sua sexualidade de maneira livre, entre outras questões. Neste contexto, o Direito será visto mais como discurso do que como norma. Aqui entram os debates em torno dos discursos, da hermenêutica, e também de uma nova metodologia para o ensino e a prática jurídica.

\section{Críticas feministas ao Direito}

Falou das insuficiências e limitações e das possibilidades do Direito. Destacou que as críticas feministas a este campo do saber vão desde a afirmação de que o Direito é patriarcal e só serve para a manutenção da dominação dos homens sobre as mulheres até aquelas que afirmam que o direito é produto e produtor da cultura. O direito é, assim como o Estado, um instrumento de dominação de uma classe sobre a outra, mas não se resume somente a essa hipótese. Neste momento falou sobre a noção de "essencialismo 
estratégico", que, em linhas gerais, significa reivindicar uma "essência" de ser homem ou mulher ou uma essência relacionada com a questão étnico racial para poder forjar um sujeito coletivo capaz de reivindicar direitos para determinado grupo. Serve também para construir alianças, demandas, entre outros, embora tenha autoras que problematizem essa estratégia. Essas críticas se confrontam e contribuem para o avanço do pensamento feminista dentro e fora do campo jurídico.

As críticas teóricas também podem ser divididas em blocos. A primeira é uma crítica à teoria, aos postulados do direito são, em regra, patriarcais. Neste contexto ela afirma que é preciso ter cuidado com a doutrina, pois esta que deve receber o tratamento que merece.

Falou que há críticas a determinadas instituições jurídicas, tais como: leis que excluem as mulheres como sujeito de direitos; normas que criminalizam o aborto; normas referentes à punição da violência doméstica, assédio sexual e moral, etc.

Destacou também a crítica ao modo como o direito é aplicado, ou seja, questiona os métodos de interpretação e de elaboração das normas. Pontuando a invisibilidade de certos sujeitos. No âmbito desta crítica, surgem proposições de novas metodologias e formações permanentes, além de mais pesquisas empíricas, e por um direito mais analítico-crítico.

\section{Teoria feminista do direito ou feminismo jurídico?}

Ela destaca que a teoria feminista do direito é vista como um conjunto de reflexões e conceituações teóricas sobre desigualdade de gênero e sua relação com o mundo jurídico. Diz que esta é mais difundida e mais reivindicada que o feminismo jurídico. Já o feminismo jurídico é um campo de reflexão e ação assumidamente feminista, e com objetivos práticos bem claros, quais sejam, incidir sobre a produção, apropriação, interpretação e aplicação das normas jurídicas, dentro e fora do sistema de justiça.

Na sequência nos pergunta se o feminismo jurídico existe de fato e como seria sua aparição concreta no cotidiano social. Ela destaca que o feminismo jurídico pode ser visto como um campo, - informando que este conceito foi emprestado de Bourdier, quando ele diz que a sociedade é constituída de vários campos, como o religioso, o político, o jurídico. E esses campos só são definidos, percebidos, quando olhamos para a realidade e vemos que compartilham das mesmas regras que certos grupos e instituições adotam. 
Por que o feminismo jurídico é menos assumido? Falar em feminismo jurídico é trazer o debate sobre feminismo para dentro do campo jurídico. $O$ feminismo jurídico não é um fim, mas sim um meio. O campo é confronto, tomada de posição, luta, tensão, reconfiguração e redistribuição do poder/saber/fazer. $O$ feminismo jurídico não tem que ser uma teoria ou movimento que confere a mulheres um pedestal específico, deve retirar as estrelas e traças diálogos mais horizontais.

Como distribuir ou compartilhar o fazer/saber deste o feminismo jurídico, notadamente o feminismo jurídico popular? Ninguém precisa ter diploma em direito, basta ter acesso à gramática jurídica; esse feminismo jurídico na prática seria a produção teórica crítica e auto crítica; a educação jurídica crítica formal ou informal, o envolvendo em projetos de extensão e em articulação com os movimentos sociais, mas sem aquela ideia de "vou levar o saber para quem não sabe"; é a incidência política e jurídica fundamental, porque o direito sozinho não altera nada; a atuação profissional socialmente comprometida; a democratização do saber/fazer, possibilitando mais empoderamento jurídico às mulheres; a defesa de projeto político mais amplo. Enfim, se o feminismo jurídico é meio e não fim, deve ter um projeto amplo, com pessoas de outros movimentos sociais que tenham o objetivo de construir uma sociedade mais igualitária, mais justa e mais democrática.

\section{Algumas autoras:}

Apresentou algumas autoras que não falam sobre o feminismo jurídico em si, mas pautam sobre o feminismo dentro do Direito.

Nos EUA, citou Kimberle Crenshaw, Katharine Barlett, Robin West, Frances Olsen, Susan Emmenegger;

Na Europa, mencinou Tamar Pitch, Carol Smart, Dove Stang Dahl;

$\mathrm{Na}$ África, fez referencia a Florita Telo;

$\mathrm{Na}$ América Latina destacou as seguintes: Alda Facio, Claudia Dominguez, Malena Costa, Haydeé Birgin, Isabel Jaramillo, Carolina Tavar, Alicia Ruiz, Lorena Fries, Roxana Vargas, Lucia de Raphael de la Madrid;

No Brasil: Valéria Pandjarijan, Salete Maria, Fabiana Severi, Eduardo Rabenhorst, Flávia Piovesan, Carmen Hein Campos, Ella Wiecco, Denise Dourado, dentre outras. 


\section{Alguns desafios e caminhos possíveis:}

Segundo a palestrante, é preciso visualizar e transformar as desigualdades de gênero a partir do campo jurídico; assumir-se enquanto movimento/pensamento nas instituições de ensino, entidades de classe, posicionar-se frente às desigualdades intra e extra mundo jurídico; é preciso realizar mais trabalho colaborativo, mais eventos, mais linhas de pesquisa, provocar mudanças na cultura jurídica acadêmica e social. 